FERMILAB-TM-2281-AD

\title{
2004 Fermilab Fall Shutdown P-Bar Water Issues
}

\author{
Albert Dyer and Frank Schneider \\ Fermilab, Batavia, IL 60510
}

I was assigned to Frank Schneider, who works within the Accelerator Division Water Group. Frank would educate me with issues pertaining to water flow cooling at the P-Bar facility. Also during the shutdown period, water issues in the Pre-Vault Stub Room would be addressed.

Week one was primarily used to familiarize and understand the tasks Frank and I were charged with. Operation of equipment as well as an overview of safety issues was presented by Frank. Once the equipment was positioned into place, "hands-on" examples to further enforce instructions given by Frank were reviewed.

Work began with Frank and I removing water hoses from magnets, which were slated for new magnet stands. These magnets were "blown-out" to prevent water from becoming stagnant within the magnet. With the completion of this task, I began "Header Flushing" as Frank began replacing water hoses, which presented a reliability hazard, in his opinion. As I understood the process of header flushing, I decided that I would use a higher water pressure than the "house pressure" in an attempt to flush each sector as thoroughly as possible. This also included cycling the power several times during the flush period to entice particle contamination to become dislodged by surging high pressure water and remove itself from the sector currently being flushed. I also kept note of any reduction in particle count as water in this closed-loop system passed through the filter. Water leaks were also noted and would be addressed at a later date.

The Header Flushing closed-loop system consisted of first closing the LCW (Low Conductivity Water) supply at the header. At one end of the sector being flushed, a jumper hose was attached between the LCW supply line and LCW return line. At the other end of the sector, the LCW supply line and LCW return line were connected to a portable water pump. The pump was connected in series to a filtration system and a Forward Scatter Turbidimeter. The Turbidimeter reads particle count based on a preselected scale. A series of pressure gauges at the water pump input and output stages, along with a pressure gauge at the filter, permitted me to maintain a desired water pressure. Obviously, a water leak within the closed-loop system would allow the water pressure to drop. Water was added from the LCW header supply valve as necessary during the flushing period.

After header flushing ran for about two minutes I felt water flow had stabilized within the system and I noted the reading on the Turbidimeter. This reading would become the high particle contamination reference point. As flushing progressed ran during the day, I noted the reduction in the particle count. I cycled the power several times during the 
flushing period to "disturb" the water and dislodge any particle contamination trapped within a magnet. Before ending the flush, another reading was noted on the Turbidimeter and this would be the low particle contamination reference point. The closed-loop system was then broken down and removed from the sector. The header sector was returned to its original state and an information tag placed on the LCW header supply valve noting the date of the flush. I repeated this procedure at each LCW header sector. What I determined as I flushed each sector was that on average, I noted a $20 \%$ drop in particle contamination count at the end of a header flush. Each header flush ran for six hours.

Addressing water leaks started as Frank and I began connecting water hoses to the magnets with the new stands first. Further inspection of hose condition at each sector followed with new hoses being added as needed. After all the hoses were once again connected and water turned on, I, several times during the week inspected each magnet for water leaks. A spreadsheet was developed noting the corrective measure taken with respect to water leaks. Frank determined what corrective measure needed to be taken to stop the leaks. Some minor leaks I corrected, others, Frank resolved. Water leak inspections occurred throughout the shutdown period every few days.

The large dipole magnets in sectors 40-50 were prepped for a "bake-out." Magnets that had an internal leak are noted in the spreadsheet. The bake-out was completed while I was away by Frank.

About mid-shutdown, Frank was now pulling “T's" for the Large Quad Magnet ( D4Q4A \& D4Q4B) installation. I was asked to locate hoses that had the older brass fittings. The locations are noted on the spreadsheet. As time permitted, Frank began replacing these older hoses with a stainless steel style after completing pulling "T's". Approximately 152 hoses were replaced overall during the shutdown for various reasons.

Hoses were also made and installed in the Pre-Vault Stub Room. I failed to note the magnet locations. A call from the Control Room concerning a major water leak at the Pre-Vault Stub Room lead to repacking a leaky ball valve and replacing gaskets on a water hose. Apparently, electricians working in the area tried to stop a minor leak...thereby causing a major leak, then left. Surveyors called the leak into the Control Room and stated what had occurred. Several weeks later Frank would replace the ball valve. Also, Frank and I provided new water hoses to a power supply shunt, which was to become operational.

Frank was then charged with installing water flow meters in the P-Bar facility. The water flow meters are located at Cable Tray D-403-3, D-203-1 and D203-3 respectively. As Frank was preforming this work, Inpeng Samayavong and I began brazing the last of the magnet water leaks. Again, information on which magnets were brazed is noted on the spreadsheet. One magnet water leak will not be corrected by brazing. It was decided that the leak was so minor and the risk of doing damage to the magnet would be much greater. The leak, located at D3Q17 will be monitored at this point. 
Frank is now connecting water flow cooling hoses to power supplies at the AP0 Target Hall, AP30 and AP50 locations as I prepare this report. The last task will be to survey all hoses and debris brought up for radioactive contamination, along with all equipment brought into the P-Bar facility. Once this is satisfied and the equipment is retuned to its proper place and the debris is disposed of, the removal our LOTO locks shall signal the completion of the tasks Frank and I were charged with during the shutdown.

This report is being presented from information provided to me by Frank and my notes between August through November 2004. 
P-Bar Water Leaks

11/16/2004

\begin{tabular}{|c|c|c|c|c|c|c|}
\hline Date & Location & Inspected by & Problem & Resolution & Corrected by & Date \\
\hline $9 / 10 / 2004$ & A6B7 & Albert & hose leak & replaced hose & Frank & $9 / 16 / 2004$ \\
\hline $9 / 10 / 2004$ & A5S7 & Albert & manifold leak, needs to be brazed & brazed leak/new fittings & Frank & $9 / 16 / 2006$ \\
\hline $9 / 10 / 2004$ & A1Q14 & Albert & shunt leak & replaced shunt & shunt personal & $9 / 13 / 2004$ \\
\hline $9 / 10 / 2004$ & TQ6 & Albert & hose to manifold leak & replaced hose & Frank & $9 / 17 / 2004$ \\
\hline $9 / 10 / 2004$ & TQ4 & Albert & 1. hose to manifold leak & replaced hose & Frank & $9 / 17 / 2004$ \\
\hline & & & 2. Copper line overhead leak & tightened connector & Frank & $9 / 17 / 2004$ \\
\hline $9 / 10 / 2004$ & D5SF15 & Albert & hose too short or manifold leak & replaced hose/brazed manifold & Frank & $9 / 16 / 2004$ \\
\hline $9 / 10 / 2004$ & D:QS304 & Albert & Supply hose to shunt & re-seated hose & Albert & $9 / 20 / 2004$ \\
\hline $9 / 10 / 2004$ & D5Q6 & Frank & bubble on hose & replaced hose & Frank & $9 / 24 / 2004$ \\
\hline $9 / 10 / 2004$ & D2Q5 & Frank & bubble on hose & replaced hose & Frank & $9 / 24 / 2004$ \\
\hline $9 / 15 / 2004$ & A1Q10 & Albert & hose seeping (1/2") black & replaced hose & Albert & $10 / 6 / 2004$ \\
\hline $9 / 15 / 2004$ & D3B13 & Albert & manifold leak, needs to be brazed & brazed leak & Samayavong & $11 / 8 / 2004$ \\
\hline $9 / 15 / 2004$ & A6Q9 & Albert & lower water tube from magnet leak & tightened connector & Frank & $9 / 16 / 2004$ \\
\hline $9 / 16 / 2004$ & D6Q11 & & backside leak upper manifold & tightened connector & Frank & $9 / 20 / 2004$ \\
\hline 9/21/2004 & AARF4 & Frank & hose leak inside cavity & tightened connector & RF Person & $9 / 22 / 2004$ \\
\hline & & & & & & \\
\hline $9 / 22 / 2004$ & D:QS509 & Albert & hose with brass fitting & replaced hose & Frank & $9 / 22 / 2004$ \\
\hline $9 / 22 / 2004$ & D:QS502 & Albert & hose with brass fitting & replaced hose & Frank & $9 / 22 / 2004$ \\
\hline $9 / 22 / 2004$ & D:QS402 & Albert & hose with brass fitting & replaced hose & Frank & $9 / 22 / 2004$ \\
\hline $9 / 22 / 2004$ & D:QS403 & Albert & hose with brass fitting & replaced hose & Frank & $9 / 22 / 2004$ \\
\hline $9 / 22 / 2004$ & D:QS406 & Albert & hose with brass fitting & replaced hose & Frank & $9 / 22 / 2004$ \\
\hline $9 / 22 / 2004$ & D4B11 & Albert & hose with brass fitting & replaced hose & Frank & $9 / 22 / 2004$ \\
\hline $9 / 24 / 2004$ & D5Q6 & Albert & 1/4" black hoses leaking (2) & replaced hoses & Frank & $9 / 27 / 2004$ \\
\hline $9 / 24 / 2004$ & D4SD10 & Albert & copper line leak, needs to be brazed & brazed leak & Samayavong & $11 / 8 / 2004$ \\
\hline $9 / 24 / 2004$ & A4B10 & Frank & lower fitting leak, black hose & replaced hose & Albert & $10 / 6 / 2004$ \\
\hline & & & & & & \\
\hline 9/27/2004 & A3Q13 & Albert & hose leak & tightened connector & Albert & $10 / 6 / 2004$ \\
\hline $9 / 27 / 2004$ & EQ6 & Albert & hose with brass fitting & & & \\
\hline $9 / 27 / 2004$ & D1Q8 & Albert & hose with brass fitting & & & \\
\hline $9 / 27 / 2004$ & D1B7 & Albert & hose with brass fitting & & & \\
\hline $9 / 27 / 2004$ & D6B7 & Albert & hose with brass fitting & & & \\
\hline $9 / 27 / 2004$ & D6Q9 & Albert & hose with brass fitting & & & \\
\hline 9/27/2004 & D6Q10 & Albert & hose with brass fitting & & & \\
\hline $9 / 27 / 2004$ & D6Q11 & Albert & hose with brass fitting & & & \\
\hline $9 / 27 / 2004$ & D6Q12 & Albert & hose with brass fitting & & & \\
\hline $9 / 27 / 2004$ & D6Q13 & Albert & hose with brass fitting & & & \\
\hline
\end{tabular}

Page 1 of 3 
P-Bar Water Leaks

$11 / 16 / 2004$

\begin{tabular}{|c|c|c|c|c|c|c|}
\hline $9 / 27 / 2004$ & SMA107 & Albert & hose with brass fitting & & & \\
\hline $9 / 27 / 2004$ & A6S10 & Albert & hose with brass fitting & & & \\
\hline & & Albert & sub-room $40-1$ hose with brass fitting & & & \\
\hline $10 / 6 / 2004$ & A3B7 & Albert & orenared maanet for bake-out & no leak & Alhert & \\
\hline $10 / 6 / 2004$ & A3B8 & Albert & prepared magnet for bake-out & major leak within magnet & Albert & $10 / 6 / 2004$ \\
\hline $10 / 6 / 2004$ & A3B9 & Albert & prepared magnet for bake-out & no leak & Albert & $10 / 6 / 2004$ \\
\hline $10 / 6 / 2004$ & A3B10 & Albert & prepared magnet for bake-out & no leak & Albert & $10 / 6 / 2004$ \\
\hline $10 / 7 / 2004$ & A4B10 & Albert & prepared maqnet for bake-out & minor leak within maqnet & Albert & $10 / 7 / 2004$ \\
\hline $10 / 7 / 2004$ & A4B9 & Albert & prepared magnet for bake-out & minor leak within magnet & Albert & $10 / 7 / 2004$ \\
\hline $10 / 7 / 2004$ & A4B8 & Albert & prepared magnet for bake-out & no leak & Albert & $10 / 7 / 2004$ \\
\hline $10 / 7 / 2004$ & A4B7 & Albert & prepared magnet for bake-out & not equipped for bake-out & Albert & $10 / 7 / 2004$ \\
\hline $10 / 7 / 2004$ & A4B3 & Albert & prepared magnet for bake-out & not equipped for bake-out & Albert & $10 / 7 / 2004$ \\
\hline $10 / 19 / 2004$ & D2SD10 & Albert & lower tube needs to be brazed & brazed leak & Samavavong & $11 / 8 / 2004$ \\
\hline $10 / 19 / 2004$ & D2SD14 & Albert & hose leak & tightened connector & Frank & $10 / 19 / 2004$ \\
\hline $10 / 19 / 2004$ & D1Q17 & Albert & hose leak & replaced 1/4" black hose & Albert & $10 / 29 / 2004$ \\
\hline $10 / 19 / 2004$ & A5Q10 & Albert & hose leak & replaced 3/8" black hose & Albert & $10 / 29 / 2004$ \\
\hline $10 / 20 / 2004$ & DQS317 & Albert & shunt leaking & replaced shunt & shunt person & $11 / 1 / 2004$ \\
\hline $10 / 20 / 2004$ & DQS319 & Albert & SS line leaking & replaced tube & Frank & $10 / 28 / 2004$ \\
\hline & & & & & & \\
\hline $10 / 25 / 2004$ & D5SD19 & Albert & hose leak & tightened hose & Albert & $10 / 28 / 2004$ \\
\hline & & & & & & \\
\hline $10 / 28 / 2004$ & D5Q12 & Albert & connected hoses & no leaks & Albert & $10 / 28 / 2004$ \\
\hline $10 / 28 / 2004$ & D5Q17 & Albert & hose leak & replaced 1/4" black hose & Albert & $11 / 2 / 2004$ \\
\hline $10 / 28 / 2004$ & D6Q17 & Albert & connected hoses & no leaks & Albert & $10 / 28 / 2004$ \\
\hline $10 / 28 / 2004$ & \begin{tabular}{|l|} 
D6SD19 \\
\end{tabular} & Albert & hose leak & tightened hose & Albert & $10 / 28 / 2004$ \\
\hline $10 / 28 / 2004$ & Q417 & Albert & replaced all \& connected hoses & no leaks & Albert & $10 / 28 / 2004$ \\
\hline $10 / 28 / 2004$ & D5Q4 & Albert & hose leak & tightened hose & Albert & $10 / 28 / 2004$ \\
\hline $10 / 28 / 2004$ & A2B9 & Albert & 3/8" black hose weeping & replaced 3/8" black hose & Albert & $10 / 28 / 2004$ \\
\hline $10 / 28 / 2004$ & D2Q13 & Albert & 1/4" black hose kinked & replaced hose & Albert & $10 / 29 / 2004$ \\
\hline $10 / 28 / 2004$ & A2Q2 & Albert & 1/4" black hose leaking & replaced hose & Albert & $10 / 29 / 2004$ \\
\hline $10 / 28 / 2004$ & D3Q5 & Albert & 1/4" black hose binding & replaced hose & Albert & $10 / 29 / 2004$ \\
\hline $10 / 28 / 2004$ & D4SF16 & Albert & hose leak & tightened hose & Albert & $10 / 29 / 2004$ \\
\hline 10/28/2004 & DQS415 & Albert & upper shunt hose leaking & tightened hose & Albert & $10 / 29 / 2004$ \\
\hline $10 / 28 / 2004$ & D6SF19 & Albert & hose leak & tightened hose & Albert & $10 / 29 / 2004$ \\
\hline $11 / 1 / 2004$ & D1SD9 & Albert & copper line needs to be brazed & brazed leak & Samayavong & $11 / 8 / 2004$ \\
\hline $11 / 1 / 2004$ & D1SF18 & Albert & brass tube needs to be brazed & brazed leak & Samayavong & $11 / 8 / 2004$ \\
\hline
\end{tabular}

Page 2 of 3 
P-Bar Water Leaks

11/16/2004

\begin{tabular}{|c|l|l|l|l|c|c|}
\hline $11 / 1 / 2004$ & D3SD12 & Albert & lower SS tube needs to be brazed & brazed leak & Samayavong & $11 / 8 / 2004$ \\
\hline & & & & & & \\
\hline $11 / 3 / 2004$ & D5SF16 & Albert & hose leak & tightened hose & Frank & $11 / 3 / 2004$ \\
\hline $11 / 8 / 2004$ & D6SD13 & Albert & minor leak needs to be brazed & brazed tube & Samayavong & $11 / 8 / 2004$ \\
\hline $11 / 12 / 2004$ & D2Q3 & Albert & SS tubing leak... bumped into & tightened hose & Frank & $11 / 12 / 2004$ \\
\hline & & & & & & \\
\hline & & & & & & \\
\hline
\end{tabular}

